\title{
Regional Evaluation of Tolerability and Efficacy of Imatinib Mesylate in Patients with Chronic Phase CML in Mashhad (Iran, Southwest Asia)
}

\author{
Zahra Mozaheb ${ }^{1}{ }^{*}$, Maeedeh Javani ${ }^{2}$ \\ ${ }^{1}$ Department of Hematology, Imam-Reza Hospital, Mashhad University of Medical Science, Mashhad, Iran \\ ${ }^{2}$ Azad University, Mashhad, Iran \\ Email: ${ }^{*}$ mozahebz@mums.ac.ir
}

Received 14 February 2014; revised 18 March 2014; accepted 26 March 2014

Copyright (C) 2014 by authors and Scientific Research Publishing Inc.

This work is licensed under the Creative Commons Attribution International License (CC BY).

http://creativecommons.org/licenses/by/4.0/

(c) (i) Open Access

\begin{abstract}
Sixty patients with Chronic Myeloid Leukemia (CML) who were on oral imatinib were included in this study. The study aimed to evaluate patients' characteristic, tolerability and efficacy and clinical outcome in Iranian patients who have been treated with generic imatinib. The median age of patients was 48 years, and the median follow up was 44 months. $94 \%$ of patients achieved complete hematologic response (CHR) during the 3 months of beginning imatinib, and after 12 - 24 months of imatinib therapy $46.8 \%$ achieved molecular response. The most common non-hematologic toxicity was fluid retention (64\%), fatigue $(43 \%)$ and moderate to severe hematologic side effect included anemia $10 \%$, neutropenia $10 \%$, and thrombocytopenia $6.6 \%$. About $13 \%$ of patients transformed into accelerated phase (AP) or blastic crisis (BC) and the death rate during this period was $7 \%$. In conclusion, there is heterogeneity in different areas in characteristic of CML (especially in age), and also response rate and side effect of patients with CML that treated with imatinib are different.
\end{abstract}

Keywords

CML, Imatinib, Adverse Effects, Response Rate

\section{Introduction}

Chronic myeloid leukemia (CML) is a myeloproliferative disorder, and characterized by a chromosomal rear-

${ }^{*}$ Corresponding author.

How to cite this paper: Mozaheb, Z. and Javani, M. (2014) Regional Evaluation of Tolerability and Efficacy of Imatinib Mesylate in Patients with Chronic Phase CML in Mashhad (Iran, Southwest Asia). Health, 6, 900-907. 
rangement of the long arms of chromosomes 9 and 22, resulting in the formation of the Philadelphia chromosome. These lead to formation of a novel fusion gene Bcr-Abl, which encodes a constitutively active tyrosine kinas in transformed cells. The treatment of CML has been revolutionized with the use of competitive inhibitor of the Bcr-Abl tyrosine kinase, imatinib mesylate [1]. Without treatment, CML progresses within several years to an accelerated phase, and ultimately to blast crisis and death. CML has been considered a prototype disease for the development of targeted therapies in the treatment of human malignancies. The goals of CML treatment include complete hematologic response, complete cytogenetic response, major molecular response, and complete molecular response. Imatinib mesylate a Bcr-Abl tyrosine kinas inhibitor, has been shown to induce dramatic hematologic and cytogenetic responses in CML [2] and remains the standard for first-line treatment of CML in chronic phase [3]. There are few studies about CML patients and their treatment in our area (Mashhad, Iran), therefore in this study we aim to study the response rate and side effect of imatinib in our CML patients to compare with the other studies.

\section{Methods}

A case series study was conducted in CML patients in out-patients hematology clinic in Mashhad University of medical science, during recent 10 years, since 2004 to 2013. We enrolled 60 CML patients in chronic phase, as defined by less than $15 \%$ blasts or basophils in peripheral blood or bone marrow [4]. Patients diagnosed by bone marrow aspiration study, cytogenetic study for Philadelphia chromosome and/or molecular study for ABL/BCR translocation by nested RT/PCR method [5]. Some patients had relapsed on hydroxyurea with or without $\alpha$-interferon therapy or they had previously failed to achieve a complete hematologic or cytogenetic response to interferon- $\alpha$. Before imatinib was started, other therapies for CML were discontinued. At first all clinical and laboratory data of patients were recorded and then all patients were treated with imatinib mesilate. Inclusion criteria included all patients diagnosed chronic phase CML which treated imatinib and their data were recorded. Exclusion criteria included CML patients with abnormal renal function, abnormal liver function or presence of any concomitant active disease that could compromise patient safety during the study. In this study all patients were informed about the study and they were satisfied. The study approved by the local ethics committee (no: 910901) and we considered the 24 items in the ethical guideline of the Iranian Ministry of Health.

Safety assessments included the evaluation of adverse effects by physical examination, hematologic assessment, and biochemical testing. Patients were evaluated monthly for all clinical and labratoary changes including anemia, splenomegally. Hematologic side effect such as leukocyte count and differentiation, hemoglobin and platelet count before and after treatment with imatinib, and non-hematologic imatinib side effect including: edema, dizziness, fatigue, gastrointestinal symptoms, bone pain, rash, pruritus, artheralgia, myalgia, hemorrhagia, red eye, and liver function test were evaluated and recorded. Toxicity was graded according to the Common Toxicity Criteria of the National Cancer Institute.

(http://ctep.info.nih.gov/protocolDevelopment/electronic applications/docs/ctcaev3.pdf). Grade Description included: 1) Mild; asymptomatic or mild symptoms; clinical or diagnostic observations only; intervention not indicated, 2) Moderate; minimal, local, or noninvasive intervention, 3) Severe or medically significant but not immediately life-threatening; hospitalization or prolongation of hospitalization indicated; disabling; limiting self-care ADL, 4) Life-threatening consequences; urgent intervention indicated.

Complete hematologic response was defined as a reduction in the white-cell count to less than $10,000 / \mathrm{mm}^{3}$ and in the platelet count to less than $450,000 / \mathrm{mm}^{3}$, maintained for at least four weeks. Patients considered imatinib-resistant with failing to have achieved a complete hematological response (CHR) by 3 months [6]. In most patients molecular response were assessed by nested RT/PCR Abl-Bcr in peripheral blood every 6 months. Quantitative RT/PCR was done only in 7 patients. The Quantitative RT/PCR test at first was not available and then was very expensive, therefore most patients did not done it; therefore we used nested PCR, which can be performed to confirm the molecular remission status.

After data collection by prepared check list, they were analyzed and compared with other studies. The SPSS software was used for statistical analysis.

\section{Results}

\subsection{Patient Characteristics}

Sixty patients with chronic phase CML, from out-patients clinic were included in this study. Median age of pa- 
tients was 48 years (range 13 - 80 years), at diagnosis about 52\% of patient were in fifth and sixth decades. Male/female ratio was 26/34. Median follow-up was 44 months (range 6 - 115 months). About 82\% of patients were in chronic phase at diagnosis. We can see other characteristic of patients in Table 1. At starting of imatinib, 13 patients were treated previously with hydroxyurea with or without $\alpha$-interferon and 47 patients were new cases.

\subsection{Evaluation of Response}

Table 2 shows the outcome of the CML patients which, at first treated with imatinib with standard dose of 400 mg per day in divided dose. The patients were followed up for median 44 month (range 8 to 115). In patients evaluation and follow up, 94\% of patients had achieved complete hematologic response (CHR) during the 3 month of beginning imatinib, and after 12 - 24 month of imatinib therapy $46.8 \%$ had achieved molecular response (undetected ABL/BCR by nested RT/PCR). Quantitative RT/PCR was done only in 7 patients; which complete molecular responses and a reduction of at least 3 log in levels of $B C R-A B L$ transcripts in peripheral blood cells were seen in 3 patients after 18 - 24 months of treatment. Dose adjustments in the course of disease occurred in 15 out of 54 of patients, and included dose escalation or reduction, for inadequate efficacy or intolerability, respectively. Imatinib interruption was done in 9 patients because of unresponsiveness or severe toxicity. During the follow-up period 8 patients progressed to accelerated or blast crisis and four patients were died.

Table 1. Characteristic of the 60 patients with CML.

\begin{tabular}{|c|c|}
\hline Characteristic & $\begin{array}{c}\text { Value } \\
\text { No. (\%) }\end{array}$ \\
\hline $\begin{array}{c}\text { Sex } \\
\text { Male } \\
\text { Female }\end{array}$ & $\begin{array}{l}26(43.3) \\
34(56.7)\end{array}$ \\
\hline $\begin{array}{l}\text { Age (year) } \\
\text { Median } \\
\text { mode } \\
\text { Minimum } \\
\text { Maximum }\end{array}$ & $\begin{array}{l}48 \\
25 \\
13 \\
80\end{array}$ \\
\hline $\begin{array}{l}\text { Stage of disease } \\
\text { Chronic phase } \\
\text { Accelerated phase } \\
\text { Blastic phase }\end{array}$ & $\begin{array}{c}49(81.7) \\
7(11.7) \\
2(3.3)\end{array}$ \\
\hline $\begin{array}{c}\text { Spleen size } \\
\text { Normal } \\
<10 \text { cm sub costal } \\
>10 \text { cm sub costal }\end{array}$ & $\begin{array}{c}14(25) \\
26(46.4) \\
16(28.6)\end{array}$ \\
\hline $\begin{array}{c}\text { History of disease no. (\%) } \\
\text { Previously treated } \\
\text { New cases }\end{array}$ & $\begin{array}{l}13(21.6) \\
47(78.3)\end{array}$ \\
\hline $\begin{array}{c}\text { Hemoglobin at base line-cells } / \mathrm{mm}^{3} \\
\text { Normal } \\
\text { Mild to moderate anemia } \\
\text { Severe anemia }\end{array}$ & $\begin{array}{l}18(34) \\
29(54) \\
6(11.3)\end{array}$ \\
\hline $\begin{array}{l}\text { White-cell count at base line-cells } / \mathrm{mm}^{3} \\
<50,000 \\
50,000-150,000 \\
150,000-300,000 \\
>300,000\end{array}$ & $\begin{array}{l}7(13.5) \\
25(48) \\
16(31) \\
3(6)\end{array}$ \\
\hline $\begin{array}{l}\text { Platelet count at base line-cells } / \mathrm{mm}^{3} \\
\text { Normal } \\
\text { High } \\
\text { Low }\end{array}$ & $\begin{array}{l}34(64) \\
18(34) \\
1(1.9)\end{array}$ \\
\hline $\begin{array}{c}\text { Hasford score } \\
\text { Low risk } \\
\text { Intermediate risk } \\
\text { High risk }\end{array}$ & $\begin{array}{c}25(43) \\
28(49) \\
4(7)\end{array}$ \\
\hline
\end{tabular}


Table 2. Follow up of patient treated with imatinib.

\begin{tabular}{cc}
\hline Follow up & $\begin{array}{c}\text { Frequency } \\
\text { No (\%) }\end{array}$ \\
\hline Increasing dose $(600-800 \mathrm{mg})$ & $10(18.5)$ \\
Decreased dose $(100-300)$ & $5(9.2)$ \\
Transformation to acute \& accelerated phase & $7(13)$ \\
Death & $4(7)$ \\
Discontinued imatinib & $9(16)$ \\
Complete hematologic response & $94 \%$ \\
Molecular response & $46.8 \%$ \\
Refer for transplantation & $2(3.3)$ \\
Median duration follow up & $44(8-115)$ month \\
Unknown cases & $6(10)$ \\
\hline
\end{tabular}

\subsection{Toxicity and Adverse Events}

We investigated a total of 18 adverse events (AE) of imatinib throughout this study period, and graded according to the Common Toxicity Criteria of the National Cancer Institute. We have grouped toxicity grades to mild, moderate, and severe for the analysis. In the first year after imatinib therapy $39 \%$ of patients had anemia, which in 2 of them was severe, but then declined to $10 \%$, and there was no severe anemia. There were 2 cases of severe

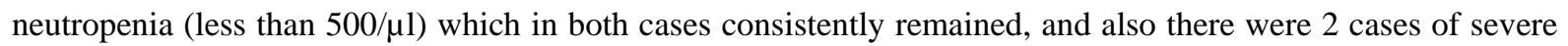

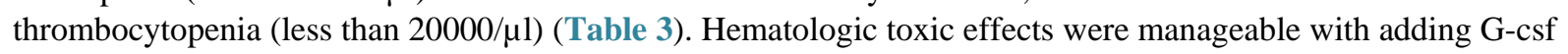
and erythropoietin into their treatment. Concurrent administration of growth factors and imatinib was well tolerated.

The most common non-hematologic toxicity was fluid retention (64\%), fatigue (43\%), musculoskeletal pain (41\%), skin rush (35\%), nausea (21\%). Severe non-hematologic toxic effects were seen in $8 \%$ (5 patients), and treatment were discontinued in 4 patients because of drug-related adverse events. In other patients the side effects were manageable, which edema and musculoskeletal pain were reduced with adding diuretics and calcium magnesium supplements, respectively, and no treatment-related deaths occurred. Hemorrhagic event were seen in 8 patients, 2 cases had sub-conjunctival hemorrhage and in 6 cases their menstruation become severe after beginning of imatinib. We can see other non-hematologic side effect in Table 4.

\section{Discussion}

There is limited study on the epidemiology and outcomes of patients in eastern countries specially in our country. Regional differences in overall survival were described with Southern/Eastern European patients having better outcomes than all other regions while patients from Africa and Latin America had worse outcomes [7]. In this study we evaluate the CML patients including patients' characteristic, response rate to imatinib and its toxicity in our area in comparison with other study.

As we can see in Table 1 the median age of our patients (Mashhad, IRAN, southwest Asia) was 48 (range 13 - 80) years at diagnosis, which is less than the median age of in western country that it is 64 years [8], but is more than some reports from eastern. In a study, age at diagnosis differed within Asia, in western Asia 44.4 years, southeastern Asia 39.5, eastern Asia 38.4, south-central Asia 37.8 were reported [7]. Approximately, fifty two percent of patients were in 5th and 6th decades, $3.3 \%$ were in 2 th decades and $10 \%$ were in 7 th and 8 th decades. In all studies CML was more commone in male [9]; but in our study in female was more common (m/f: 26/34); the reason was the gender of our physician, which was female. In our country some women prefer to be visited by female physician. At diagnosis about $82 \%$ of patients were in chronic phase, and based on Hasford score $43 \%$ of patients were low risk, 49 intermediate risk and $7 \%$ were high risk, most patients who had molecular response were in intermediate risk, but difference was not significant.

At median follow up of 44 month (8 - 115 month) the hematologic response for our patients were $94 \%$ and molecular response (undetected ABL/BCR by nested RT/PCR) were $47 \%$. At median 44 months follow up, the estimated rate of event-free survival was $65 \%$, and during the follow up $18 \%$ of patients had hematologic failure 
Table 3. Hematologic side effect of imatinib.

\begin{tabular}{cccccc}
\hline $\begin{array}{c}\text { Hematologic } \\
\text { Side effect }\end{array}$ & $\begin{array}{c}\text { Mild } \\
\text { No (\%) }\end{array}$ & $\begin{array}{c}\text { Moderate } \\
\text { No (\%) }\end{array}$ & $\begin{array}{c}\text { Severe } \\
\text { No (\%) }\end{array}$ & $\begin{array}{c}\text { Total } \\
\text { No (\%) }\end{array}$ & $\begin{array}{c}\text { Total SE\% } \\
\text { mod-severe }\end{array}$ \\
\hline Anemia, before 1 y & $19(32.8)$ & $21(36)$ & $2(3.3)$ & $42(72)$ & 39.3 \\
Anemia, after 1 y & $17(28)$ & $6(10)$ & - & $21(35)$ & 10 \\
Neutropenia & $5(9.8)$ & $2(3.3)$ & $2(3.3)$ & $9(15)$ & 6.6 \\
Thrombocytopenia & $4(6.6)$ & $4(6.6)$ & $2(3.3)$ & $10(16.7)$ & 10 \\
\hline
\end{tabular}

Table 4. Common non-hematologic side effects of imatinib.

\begin{tabular}{cccc}
\hline $\begin{array}{c}\text { Non-hematologic } \\
\text { side effect }\end{array}$ & $\begin{array}{c}\text { Mild-moderate } \\
\text { No (\%) }\end{array}$ & $\begin{array}{c}\text { Severe } \\
\text { No (\%) }\end{array}$ & (Total) \% \\
\hline Fluid retention & $31(56.4)$ & $4(7.3)$ & 63.7 \\
Fatigue & $26(43)$ & - & 43 \\
Musculoskeletal pain & $21(37)$ & $2(3.6)$ & 40.6 \\
Skin rash & $17(28.3)$ & $4(6.6)$ & 35 \\
Nausea & $13(21.3)$ & $2(3.3)$ & 24.6 \\
Myalgia & $13(23)$ & - & 23 \\
Dizziness & $12(21.8)$ & - & 21.7 \\
Pruritus & $7(11.7)$ & $6(10)$ & 14.3 \\
Bleeding tendency & $8(14.3)$ & - & 10 \\
Arthralgia & $6(10)$ & - & 9.6 \\
Liver toxicity & $5(9.6)$ & $1(1.9)$ & 5 \\
Infection & $3(5)$ & - & 5 \\
Red eye & $3(5)$ & - & 3.3 \\
Vomiting & $2(3.3)$ & - & 1.7 \\
\hline
\end{tabular}

and needed imatinib dose escalation from 400 to 600 or $800 \mathrm{mg}$ daily. After a median follow-up of 36 months from dose escalation, $70 \%$ of them remained alive. About $13 \%$ of patients transformed into accelerated phase (AP) or blastic crisis (BC) and the death rate during this period was 7\%. In the study of A Hochhaus and colleague the estimated rate of freedom from progression to AP and BC was 93\% [10]. In the other Iranian study their hematologic response and molecular response were $86 \%$ and $46 \%$ respectively [11]. In most other study hematologic response were more than $95 \%$, and in a study of the 553 patients receiving imatinib, $6 \%$ progressed to the accelerated phase or blast crisis, $3 \%$ had a hematologic relapse, $5 \%$ had a loss of major cytogenetic response [12] [13]. Four year survival rate in our study was $65 \%$, but in the IRIS trial demonstrated that after 5 years of imatinib therapy, the overall survival of patients was $89 \%$, and in a study of 279 newly diagnosed patients presenting to the MD Anderson Hospital an estimated 3-year survival rate was 96\% [14]. The estimated risk of disease progression and death rate was slightly higher in our patients and overall survival less than mentioned studies. In contrast previous mention clinical trial, the population-based study showed that, at 24 months $49 \%$ (27 of 55 assessable cases) had failed or were intolerant of imatinib and they suggested that caution is needed in extrapolating clinical trial data to the general CML population [15].

After a median follow-up of 44 months, non-hematologic adverse effects reported were relatively similar to those reported previous study, some of them slightly more and some slightly less. The most commonly reported adverse events were edema (including peripheral and periorbital edema) (63\%), in 4 patients there were grade 3 or 4 toxicity, in one patient imatinib was stopped, in the others were tolerable without treatment or were controlled by diuretics. Fatigue were seen in (43\%), it seems that most patients had fatigue because of their anemia. Skin rash were seen in (35\%), in 4 patients were grade 3 or 4 toxicity. Imatinib were discontinued in 2 patients 
because of the severity of nausea, and only one patient had vomiting. Other gastrointestinal side effects such as diarrhea and abdominal pain in our patients were not seen, while in the IRIS trial diarrhea in $45 \%$ and abdominal pain in $37 \%$ were reported [12]. All other side effects was mild and nobody needed additional medication. Only one patient had severe liver toxicity (Grade 3 or 4 ) leading to discontinuation of the imatinib. From $14 \%$ of patients who had hemorrhage, 2 patients had subconjunctival hemorrhage, and in others (women) the menstruation period were became intense; after starting imatinib. Eye complication other than periorbital edema were including red eye in 5\%, which in one patient was recurrent, and subconjunctival hemorrhage in two patients (3.3\%), which were rarely reported in other studies even in the studies that evaluated ocular adverse effects [16] [17]. Subconjunctival hemorrhage in one patient occurred with thrombocytopenia, but the other patient did not have. In a Iranian study which were used generic imatinib, like our patients, adverse effects were as follows: edema (63\%), GI symptoms (40\%), fatigue and headache (40\%), mood symptoms (13\%), and hematological complications (9.3\%) [11].

Hematologic Adverse events consisted of mild to moderate reduction in hemoglobin level were seen in most patients (total anemia in 39.3\%) during first 6 - 12 month, but after that the hemoglobin level increased with continued therapy (total anemia in 10). Mild to moderate neutropenia in $13 \%$ of patients, and severe neutropenia which patients had been required G-CSF were seen in 3.3\%. 16.7\% of patients had thrombocytopenia, but only one patient had been bleeding (sub-conjunctival hemorrhage), because of severe thrombocytopenia. Neutropenia and thrombocytopenia in this study was slightly more than other adverse effects were reported [12], and anemia in our study was significantly more common in comparison other studies; although in most studies anemia was not reported. Anemia in our study was been more common in women $(\mathrm{m} / \mathrm{f}=0.6)$, which some of them may be related to the severity of menstruation in the women. During the follow up period worsening or new toxicities were not common. Grade 3 or 4 neutropenia was noted during the MD Anderson cancer center study in 35 percent of the patients treated with $800 \mathrm{mg}$ imatinib, and thrombocytopenia was found in 20 percent of the patients [14]. In the randomized trial of newly diagnosed patients in the chronic phase who received imatinib at 400 $\mathrm{mg} /$ day, grade 3 neutropenia was experienced by $11 \%$ of patients, grade 4 neutropenia occurred in $2 \%$ of patients, grade 3 thrombocytopenia occurred in $6.9 \%$ of patients, and grade 4 thrombocytopenia occurred in less than $1 \%$ of patients [18]. In our patients, infection were seen only in 2 neuropenic patients, in both of them infection was controlled, while in a elderly study 9 patients (25\%) experienced an infection episode during the follow-up, and in two cases the patients finally died because of the infection [19]. In a study with $800 \mathrm{mg}$ imatinib, grade 3 thrombocytopenia and neutropenia occurred in $16 \%$ and $14 \%$ of patients, respectively [20]. Based this studies most adverse effects increased in incidence and severity at the higher doses.

Serious drug-related adverse events were reported in 7 patients (11 percent), and drug-related adverse events including, nausea (2 patients), hepatic toxic effects (1 patient), edema and skin rash (2 patients), severe netropenia (2 patients) led to the discontinuation of therapy in 5 patients ( 8 percent). We did not and death related to drug toxicity. $7 \%$ death rate in our study related to progression of disease and unresponse to therapy. In a study drug-related adverse events led to the discontinuation of therapy in 11 patients (2.1\%), and only $2 \%$ of patients discontinued treatment because of drug-related adverse events, and no treatment-related deaths occurred [21].

There are several limitations in this study. At first most patients did not take original imatinib, in addition our patients did not done quantitative RT/PCR for evaluation of molecular response. Also limitation of sample size of this study induces some variation in the results.

\section{Conclusion}

In conclusion, based on these data and comparing with other studies, there is heterogeneity in age at diagnosis of CML, it may be related to genetic, environmental, or biologic factors. Also overall survival has been shown to differ by and within regions. But these differences also were seen between some clinical trial data and population study. Common side effects of imatinib were relatively similar and comparable to others, but hematologic toxicities were different. All these differences may be due to the effect of biological, environmental, or socioeconomic factors, and/or the imatinib which was used.

\section{Acknowledgements}

This work was supported by a grant from the deputy of research at medical school No. 910901. 


\section{Disclosure Statement}

The authors declare no conflict of interest.

\section{References}

[1] Larson, R.A., Druker, B.J., Guilhot, F., O’Brien, S.G., Riviere, G.J., Krahnke, T., et al. (2008) Imatinib Pharmacokinetics and Its Correlation with Response and Safety in Chronic-Phase Chronic Myeloid Leukemia: A Subanalysis of the IRIS Study. Blood, 111, 4022-4028. http://dx.doi.org/10.1182/blood-2007-10-116475

[2] Ali, R., Özkalemkaş, F., Özçelik, T., Özkocaman, V., Ozan, Ü., Kimya, Y., et al. (2005) Pregnancy under Treatment of Imatinib and Successful Labor in a Patient with Chronic Myelogenous Leukemia (CML): Outcome of Discontinuation of Imatinib Therapy after Achieving a Molecular Remission. Leukemia Research, 29, 971-973. http://dx.doi.org/10.1016/j.leukres.2005.01.009

[3] Agis, H., Sperr, W., Herndlhofer, S., Semper, H., Pirc-Danoewinata, H., Haas, O., et al. (2007) Clinical and Prognostic Significance of Histamine Monitoring in Patients with CML during Treatment with Imatinib (STI571). Annals of Oncology, 18, 1834-1841. http://dx.doi.org/10.1093/annonc/mdm343

[4] Druker, B.J., Talpaz, M., Resta, D.J., Peng, B., Buchdunger, E., Ford, J.M., et al. (2001) Efficacy and Safety of a Specific Inhibitor of the BCR-ABL Tyrosine Kinase in Chronic Myeloid Leukemia. New England Journal of Medicine, 344, 1031-1037. http://dx.doi.org/10.1056/NEJM200104053441401

[5] Hughes, T.P., Kaeda, J., Branford, S., Rudzki, Z., Hochhaus, A., Hensley, M.L., et al. (2003) Frequency of Major Molecular Responses to Imatinib or Interferon Alfa plus Cytarabine in Newly Diagnosed Chronic Myeloid Leukemia. New England Journal of Medicine, 349, 1423-1432. http://dx.doi.org/10.1056/NEJMoa030513

[6] Bixby, D. and Talpaz, M. (2010) Seeking the Causes and Solutions to Imatinib-Resistance in Chronic Myeloid Leukemia. Leukemia, 25, 7-22. http://dx.doi.org/10.1038/leu.2010.238

[7] Mendizabal, A.M., Garcia-Gonzalez, P. and Levine, P.H. (2013) Regional Variations in Age at Diagnosis and Overall Survival among Patients with Chronic Myeloid Leukemia from Low and Middle Income Countries. Cancer Epidemiology, 37, 247-254. http://dx.doi.org/10.1016/j.canep.2013.01.002

[8] Howlader, N., Noone, A., Krapcho, M., Neyman, N., Aminou, R., Altekruse, S., et al. (2012) SEER Cancer Statistics Review, 1975-2009 (Vintage 2009 Populations). National Cancer Institute, Bethesda.

[9] Amirzargar, A., Bagheri, M., Ghavamzadeh, A., Alimoghadam, K., Khosravi, F., Rezaei, N., et al. (2005) Cytokine Gene Polymorphism in Iranian Patients with Chronic Myelogenous Leukaemia. International Journal of Immunogenetics, 32, 167-171. http://dx.doi.org/10.1111/j.1744-313X.2005.00502.x

[10] Hochhaus, A., O’Brien, S.G., Guilhot, F., Druker, B.J., Branford, S., Foroni, L., et al. (2009) Six-Year Follow-Up of Patients Receiving Imatinib for the First-Line Treatment of Chronic Myeloid Leukemia. Leukemia, 23, 1054-1061. http://dx.doi.org/10.1038/leu.2009.38

[11] Moshfeghi, K., Nazemzadeh, N., Mehrzad, V., Hajiannejad, A. and Esmaili, F. (2013) Comparison of Effectiveness and Safety of Iranian-Made vs. Indian-Made Imatinib in Treatment of Chronic Myeloid Leukemia. Advanced Biomedical Research, 2, 17. http://dx.doi.org/10.4103/2277-9175.108000

[12] Druker, B.J., Guilhot, F., O’Brien, S.G., Gathmann, I., Kantarjian, H., Gattermann, N., et al. (2006) Five-Year FollowUp of Patients Receiving Imatinib for Chronic Myeloid Leukemia. New England Journal of Medicine, 355, $2408-2417$. http://dx.doi.org/10.1056/NEJMoa062867

[13] Cortes, J., Giles, F., O’Brien, S., Thomas, D., Garcia-Manero, G., Rios, M.B., et al. (2003) Result of High-Dose Imatinib Mesylate in Patients with Philadelphia Chromosome-Positive Chronic Myeloid Leukemia after Failure of Interferon- $\alpha$. Blood, 102, 83-86. http://dx.doi.org/10.1182/blood-2003-01-0025

[14] Kantarjian, H.M., Talpaz, M., O’Brien, S., Jones, D., Giles, F., Garcia-Manero, G., et al. (2006) Survival Benefit with Imatinib Mesylate versus Interferon- $\alpha$-Based Regimens in Newly Diagnosed Chronic-Phase Chronic Myelogenous Leukemia. Blood, 108, 1835-1840. http://dx.doi.org/10.1182/blood-2006-02-004325

[15] Lucas, C.M., Wang, L., Austin, G.M., Knight, K., Watmough, S.J., Shwe, K.H., et al. (2008) A Population Study of Imatinib in Chronic Myeloid Leukaemia Demonstrates Lower Efficacy than in Clinical Trials. Leukemia, 22, 19631966. http://dx.doi.org/10.1038/leu.2008.225

[16] Fraunfelder, F.W., Solomon, J., Druker, B.J., Esmaeli, B. and Kuyl, J. (2003) Ocular Side-Effects Associated with Imatinib Mesylate (Gleevec $\left.{ }^{\circledR}\right)$. Journal of Ocular Pharmacology and Therapeutics, 19, 371-375. http://dx.doi.org/10.1089/108076803322279426

[17] Breccia, M., Gentilini, F., Cannella, L., Latagliata, R., Carmosino, I., Frustaci, A., et al. (2008) Ocular Side Effects in Chronic Myeloid Leukemia Patients Treated with Imatinib. Leukemia Research, 32, 1022-1025.

http://dx.doi.org/10.1016/j.leukres.2007.10.016 
[18] Deininger, M.W., O’Brien, S.G., Ford, J.M. and Druker, B.J. (2003) Practical Management of Patients with Chronic Myeloid Leukemia Receiving Imatinib. Journal of Clinical Oncology, 21, 1637-1647.

http://dx.doi.org/10.1200/JCO.2003.11.143

[19] Sánchez-Guijo, F.M., Durán, S., Galende, J., Boqué, C., Nieto, J.B., Balanzat, J., et al. (2011) Evaluation of Tolerability and Efficacy of Imatinib Mesylate in Elderly Patients with Chronic Phase CML: ELDERGLI Study. Leukemia Research, 35, 1184-1187. http://dx.doi.org/10.1016/j.leukres.2011.01.017

[20] Druker, B.J. (2002) Imatinib and Chronic Myeloid Leukemia: Validating the Promise of Molecularly Targeted Therapy. European Journal of Cancer, 38, S70-S76. http://dx.doi.org/10.1016/S0959-8049(02)80606-2

[21] Kantarjian, H., Sawyers, C., Hochhaus, A., Guilhot, F., Schiffer, C., Gambacorti-Passerini, C., et al. (2002) Hematologic and Cytogenetic Responses to Imatinib Mesylate in Chronic Myelogenous Leukemia. New England Journal of Medicine, 346, 645-652. http://dx.doi.org/10.1056/NEJMoa011573 